\title{
O Negro no Recôncavo da Bahia: reflexões sobre construções identitárias, retóricas de etnicidade, raça e cultura
}

\author{
Ana Paula Comin de Carvalho ${ }^{1}$ \\ Mariana Balen Fernandes ${ }^{1}$ \\ ${ }^{1}$ Universidade Federal do Recôncavo da Bahia, BA, Brasil
}




\section{Resumo}

O presente artigo tem o objetivo de refletir sobre os limites do reconhecimento público e político da população negra no estado da Bahia. Para tanto, realizamos uma análise comparativa dos contextos etnográficos do chamado turismo étnico-afro e de identificação, regularização e proteção dos territórios quilombolas frente a projetos de desenvolvimento na região do Recôncavo. Em ambos os casos, atentamos para as construções identitárias, retóricas da etnicidade, raça e cultura que emergem nesses processos e o quanto elas são aceitas ou não pelos diferentes agentes envolvidos. Evidencia-se a grande resistência por parte tanto do Estado quanto da sociedade em reconhecer o negro como sujeito político ou de direito, mas, tão somente, como objeto cultural, marco da identidade regional e nacional brasileira. Desse modo, a cultura continua sendo o lugar por excelência reservado aos afro-brasileiros, isto é: o espaço da diferença.

Palavras-chave: Reconhecimento Cultural. Reconhecimento Territorial. Etnicidade. Turismo.

\section{Abstract}

This article aims to reflect on the limits of public and political recognition of the black population in the state of Bahia. For this, we perform a comparative analysis of the ethnographic contexts of the so-called afro-ethnic tourism and of identification, regularization and protection of the quilombolas territories in front of development projects in the Recôncavo region. In both cases we look at the identity, rhetorical constructs of ethnicity, race and culture that emerge in these processes and how they are accepted or not by the different agents involved. There is evidence of strong resistance on the part of both the State and society to recognize the black as a political or legal subject, but only as a cultural object, a landmark of brazilian regional and national identity. In this way, culture remains the place par excellence reserved for afro-brazilians, that is, the space of difference.

Keywords: Cultural Recognition. Territorial Recognition. Ethnicity. Tourism. 


\section{Introdução}

Presente artigo tem o objetivo de refletir sobre os limites do reconhecimento público, cultural e político da população negra no Estado da Bahia. Para tanto, realizamos uma análise comparativa dos contextos etnográficos do chamado turismo étnico-afro e de identificação, regularização e proteção dos territórios quilombolas frente a projetos de desenvolvimento na região do Recôncavo. Tomamos como universos empíricos: a exploração turística da Festa da Boa Morte e das comunidades remanescentes de quilombos, ambas no município de Cachoeira; e os conflitos enfrentados por várias comunidades remanescentes de quilombos do Recôncavo nos seus processos de regularização fundiária, em especial, a partir da implantação de um complexo turístico de âmbito internacional na Ilha de Cajaíba, entre os municípios de Santo Amaro e São Francisco do Conde, e de um empreendimento naval na cidade de Maragojipe.

Em ambos os casos atentamos para as construções identitárias, retóricas da etnicidade, raça e cultura que emergem nesses processos e o quanto elas são aceitas ou não pelos diferentes agentes envolvidos. Práticas e manifestações culturais tidas como tradicionais são acionadas nos dois contextos com sentidos, intencionalidades e resultados distintos como veremos posteriormente.

As identidades são os resultados de jogos de semelhança e de diferenciação. Esses jogos são, eminentemente, linguageiros. São jogos discursivos e narrativos que vão desde um modo de contar a história (valorizando arquivos, eliminando outros; estatuindo continuidades, descontinuidades e cortes; fazendo falar certos documentos e calando outros), a produção literária e artística (cinema, vídeo e teledramaturgia), 
a valorização de certa produção musical popular, a produção simbólica midiática (meios de comunicação em geral), até anedotas, piadas e ditos populares. Tudo isso conforma um modo de ver a si mesmo e aos outros. Existem, portanto, modos do negro se ver e ser visto que é preciso investigar (FRANCISCO, 2000; CARVALHO, 2003). É o que pretendemos fazer a seguir, com ênfase para a Bahia e o Recôncavo em particular.

\section{A Festa da Boa Morte e a Rota da Liberdade}

A Festa da Boa Morte é realizada por uma irmandade de mesmo nome que surgiu entre 1820 e $1850^{1}$ na cidade de Cachoeira, distante $110 \mathrm{~km}$ de Salvador. Ela é formada exclusivamente por mulheres negras de meia idade ou anciãs, devotas de Nossa Senhora e praticantes de religiões de matriz africana ${ }^{2}$. A celebração ocorre durante o mês de agosto, no período de 13 a 17. Durante esses dias, realizam-se missas, procissões, ceias e sambas de roda em homenagem à santa.

A partir da década de 1970, a Irmandade e a Festa da Boa Morte começaram a ser exploradas turisticamente. No primeiro Planejamento de Turismo do Recôncavo de 1971, já havia uma ação específica de apoio e publicização da confraria. Entretanto, as interferências governamentais só se efetivaram após o reconhecimento do significativo afluxo de turistas estrangeiros para a celebração. Essa procura aconteceu graças a mediação de pessoas como Jimmy Lee, negro norte-americano, agente de viagens no Brasil e nos EUA, que conheceu a irmandade e a festa em uma de suas visitas a Bahia no início da década de 1970 e no ano de 1976 passou a trazer turistas norte-americanos para conhecer a confraria e seus rituais (CASTRO, 2005).

Os visitantes estrangeiros - pesquisadores, estudantes e militantes - que inicialmente totalizavam quatrocentas pessoas foram tornandose mais numerosos a cada ano. Esses foram os primeiros passos para a configuração de um turismo de "raízes africanas" ou "étnico (afro)" na cidade. Esse tipo de turismo constituiu-se originalmente em um fenômeno de retorno simbólico a uma terra natal, ancestral e contemporaneamente na busca por referências identitárias de um passado africano, pelo conhecimento das culturas negras diaspóricas 
ou pela possibilidade de estabelecimento de uma conexão com outros povos afrodescendentes (QUEIROZ, 2008).

Enquanto a experiência de participar da Festa da Boa Morte era divulgada pelos que aqui estiveram aos seus parentes e amigos estimulando a viagem deles ao país, a Bahia e ao município de Cachoeira, o governo estadual, através da Secretaria do Turismo e da Bahiatursa ${ }^{3}$, vai transformando gradativamente a irmandade em um dos ícones da marca Bahia no mercado turístico por meio de publicação de artigos e ensaios fotográficos dela dentro e fora do país. Para destacar o estado no mercado, os gestores do turismo apostavam num discurso de uma Bahia negra, onde se pratica o samba-de-roda cotidianamente, se cultiva a malícia da capoeira, se encarna o exótico, o misticismo e o sincretismo religioso, de um passado que não passa (CASTRO, 2005). A Irmandade da Boa Morte e suas celebrações, na medida em que parecem congregar grande parte desses elementos, torna-se algo a ser explorado turisticamente

Se de um lado o afluxo de turistas negros norte-americanos vai resultar em apoio para a irmandade obter uma sede própria, de outro ele vai ser o estopim para alguns conflitos. Em 1996, a Prefeitura - que até então ignorava as celebrações - vai patrocinar atividades e shows em paralelo aos rituais com o intuito de atrair mais visitantes. As irmãs expressam sua preocupação com a espetacularização e banalização da festa. No início dos anos 2000, a irmandade teve que contratar seguranças para garantir a integridade física de suas integrantes durante os cortejos e procissões da festa e protegê-las do intenso assédio dos turistas, pesquisadores, cineastas e fotógrafos. A tensão chega a seu ápice no ano de 2002, quando as irmãs ameaçam não realizar a festa devido às inúmeras atitudes desrespeitosas, como a alteração dos dias de celebração pelo poder público municipal para os finais de semana para beneficiar o turismo local. Até 1990, elas seguiam o calendário religioso católico, situação que só voltou a acontecer a partir de 2005.

Em 1989, a Igreja Católica e a Irmandade da Boa Morte vivenciam uma disputa que chegou às vias judiciais. Até então as doações para a festa e a irmandade eram controladas pela igreja. A fim de poder receber uma doação da família de Martin Luther King sem que ela 
fosse repassada a igreja - exigência postulada pelos doadores - a irmandade fez reformulações no seu estatuto que foram contestadas pelo pároco local. A própria igreja tentou elaborar um novo estatuto alterando, dentre outras coisas, a participação exclusiva de mulheres negras, mas isso não foi aceito pelas irmãs. Em uma reunião entre as partes, os religiosos teriam sido extremamente grosseiros com as irmãs, taxando-as de "negras artistas da cultura, que nada tinham a ver com religião". Posteriormente o pároco local reteve as imagens das santas de Nossa Senhora da Glória e Nossa Senhora da Boa Morte e joias e só as liberou as irmãs sob ordem judicial. Nesse processo, o movimento negro organizado lançou um manifesto em apoio a Irmandade e denunciando o racismo experienciado por ela na interação com a Igreja Católica, o que provoca declarações de cunho conciliatório por parte dos seus representantes (SOUZA, 2006). O processo de autonomização da confraria em relação à igreja ocorre com a introdução de novos mediadores, como a advogada que a representa judicialmente na questão com o pároco local e que permanece assessorando-a em todos os temas dali por diante.

Delineia-se, assim, um cenário de constante luta da irmandade pelo respeito às suas tradições - seja por parte dos visitantes, do poder público ou da igreja - que vai culminar com a demanda pelo reconhecimento cultural junto ao governo estadual em 2009. Nesse mesmo ano, o Instituto de Patrimônio Artístico e Cultural da Bahia (IPAC) inicia o processo de registro da Festa da Boa Morte com a realização de um dossiê. Em 2010, ela é inscrita no Livro de Festas e Celebrações por meio do Decreto n. 12.227. Em relação a isso, cabe destacar duas questões: o processo mais amplo em âmbito internacional, nacional e estadual de reconhecimento de bens culturais relacionados com a população negra brasileira ${ }^{4}$ no qual essa demanda se insere e as consequências da incorporação de mediadores a estrutura da irmandade - como uma advogada e um administrador - que se ocupam exclusivamente da relação do grupo com os demais, tarefa que antes era acumulada pelas próprias irmãs. Esses mediadores vão ser aqueles agentes que se relacionam com diferentes espaços sociais (o campo jurídico, estatal, dentre outros), transcodificando informações, interligando- 
os à Irmandade da Boa Morte e influenciando nas várias dimensões pertinentes ao grupo (WOLF, 2003).

A despeito da obtenção de edificações próprias, resultantes de doações de estrangeiros e de reformas promovidas pelo governo do estado a partir de apelos de intelectuais, personalidades e políticos; da visibilidade promovida pela turistização da celebração e do reconhecimento estatal como patrimônio cultural; a Festa da Boa Morte continua sendo considerada pelos moradores do município de Cachoeira como um evento para estrangeiros, em contraposição a Festa D'Ajuda5, que é tida como uma celebração mais profana e com intensa participação popular e local.

Quando a "Boa Morte acontece", como se costuma dizer, a maior parte da população e que não tem conexões com a irmandade se envolve em suas atividades pela via do comércio e prestação de serviços, visto que a cidade se transfigura nesse período. Restaurantes e bares são abertos apenas para o evento e oferecem "comidas étnicas", sendo a maniçoba a principal delas. Os já existentes modificam seus cardápios usuais, destacando a oferta do referido prato e de outros associados à culinária africana e baiana, como a moqueca. Lojas temporárias e vendedores ambulantes oferecem tecidos, vestidos, turbantes, brincos e colares com motivos étnicos (em geral estampas de tigre, zebra, onça, ou peças com cores associadas ao continente africano ou aos seus países, como o verde, vermelho, preto, bijuterias e joias com búzios, conchas, cordas, madeira, etc.).

O arrocha e o pagode, trilha sonora musical habitual das casas e ruas é substituído pelo som de atabaques. Os atendentes desses estabelecimentos e as baianas de acarajé vestem trajes especiais, que não são utilizados nos demais dias do ano. Turbantes na cabeça, guias nos pescoços, vestido branco e rodado de baiana. Filhas de Santo paramentadas com roupas brancas bordadas a mão jogam pipoca, alfazema e benzem com feixes de folhas verdes os transeuntes. Os habitantes locais agenciam todos os elementos que consideram tipicamente africanos, conforme seu imaginário, que remete em grande medida ao que já vem sendo abordado pelo turismo, meios de comunicação, literatura, pesquisa acadêmica, dentre outros, no 
intuito de corresponder ao que se acredita que os turistas querem ver e reconhecer como negro.

Não se trata aqui de propor uma discussão sobre encenação da identidade muito recorrente no âmbito dos estudos sobre turismo, mas de evidenciar que, muitas vezes, para uma identidade ser reconhecida pelos demais ela precisa apresentar um repertório de elementos tidos como autênticos e tradicionais que comuniquem essa diferença. E o poder de definição do que se configura como tal muitas vezes não está nas mãos dos grupos que reivindicam uma identidade específica, mas nas daqueles que tem a legitimidade para falar sobre. O modelo nativo de identidade étnica oferece a um indivíduo uma autoimagem e serve para ele como cânone geral para avaliação tanto do seu comportamento como dos demais que fazem parte do seu grupo. Contudo, ele só será mantido se oferecer uma autoimagem que possa ser posta em prática e que seja moderadamente consistente com as sanções que são experimentadas nas interações sociais (BARTH, 2000).

A exibição desse repertório de influência africana ou propriamente negro não se restringe a festa. Em 2012, as Comunidades Remanescentes de Quilombo do Iguape implantaram o projeto "Rota da Liberdade", uma iniciativa de turismo étnico de base comunitária, em parceria com o Instituto Votorantin, o Serviço Brasileiro de Apoio às Micro e Pequenas Empresas (SEBRAE) e Instituto Brasileiro de Educação em Negócios Sustentáveis (IBENS) e com o apoio da Setur. Durante os festejos da Boa Morte, duas vans levam os visitantes da cidade para realizar roteiros nas comunidades de Caonge, São Francisco do Paraguaçu, Dendê, Engenho da Ponte, Engenho da Praia e Camboa, localizadas no Vale do Iguape, zona rural do município. Neles, os turistas podem acompanhar a produção de farinha de mandioca, do azeite de dendê, de xaropes naturais, ter contato com rezadeiras e griôs dos terreiros, assistir palestras e apresentações culturais (como esmola cantada e samba de roda), passear de barco, visitar igrejas e ruínas de edificações construídas com mão de obra escrava que remontam ao período colonial e comprar produtos artesanais dos grupos. Dezenove guias locais foram capacitados em história e geografia regionais, primeiros socorros e condução de trilhas para orientar os visitantes. Os elementos que 
compõem os três tipos de roteiros disponíveis - dia a dia, histórico e trilha griô caravana dos orixás - foram selecionados a partir de pesquisas realizadas pelos próprios integrantes das comunidades quilombolas no âmbito de atividades dos Pontos de Cultura, projetos financiados pelo Ministério da Cultura em parceria com os governos estaduais e desenvolvidos por organizações como o Centro de Educação e Cultura do Vale do Iguape.

Integrantes das comunidades quilombolas divulgam os roteiros num estande no perímetro urbano de Cachoeira, nas imediações das celebrações da Boa Morte, ostentando turbantes nos cabelos, colares nos pescoços, vestindo roupas de algodão cru ou de estampas tidas como "africanas" e com os pés descalços. Dessa forma, os quilombolas e o seu modo de vida, ou melhor a seleção daqueles aspectos que despertam o interesse e a curiosidade sobre, podem ser conhecidos ou vivenciados por algumas horas ou dia inteiro.

Observamos, nesse caso, o mesmo processo de ênfase de alguns aspectos da identidade afrobrasileira (religiosidade, vestimenta, adereços, musicalidade, culinária) identificado entre os moradores do perímetro urbano no contexto da festa. O fato de tais elementos também comporem o imaginário do senso comum, em especial dos visitantes de fora da Bahia e do Brasil, e de serem legitimados por discursos turísticos e até mesmo acadêmicos, não quer dizer que eles não integrem de fato as retóricas nativas sobre raça, etnia e cultura, mas que ganham um estatuto especial nesses momentos de celebração. Parece-nos de fundamental importância entender por que e como isso acontece.

Tal iniciativa de turismo quilombola, como já foi dito, conta com apoio governamental para sua ampla divulgação. Embora ela receba mais visitantes estrangeiros durante a Festa da Boa Morte, os roteiros são realizados ao longo de todo o ano para turistas eventuais e escolas particulares dos municípios de grande e médio porte mais próximos. Situação não tão favorável a esses mesmos grupos se observa quando consideramos o reconhecimento territorial pleiteado por elas junto ao Estado, evidenciando um descompasso entre esses dois planos. Enquanto o turismo étnico de base comunitária prospera, a regularização 
fundiária das mesmas coletividades é lenta, sofre questionamentos administrativos e judiciais, é ameaçada ou complexificada por grandes empreendimentos privados de interesse estatal. É o que abordaremos a seguir.

\section{A Regularização dos Territórios das Comunidades Remanescentes de Quilombos do Recôncavo e Grandes Empreendimentos}

No Recôncavo da Bahia, 31 comunidades foram certificadas pela Fundação Cultural Palmares (FCP) e possuem processo de regularização fundiária em curso junto ao Instituto Nacional de Colonização e Reforma Agrária (INCRA). Como podemos observar no Quadro 1, as primeiras autoidentificações como quilombolas, isto é, ações desses grupos no sentido de afirmarem-se como tais perante o Estado, remontam ao ano de 2004. Foi a partir de discussões realizadas no Centro de Educação e Cultura do Vale do Iguape (CECVI) que essas demandas emergiram. No ano seguinte foi formado o Conselho Quilombola do Vale do Iguape que na atualidade congrega 14 comunidades da região (CRUZ, 2012). Cabe ressaltar também o papel do Conselho Pastoral dos Pescadores (CPP) na mobilização dessas coletividades (ZAGATTO,2011), bem como da Associação de Advogados de Trabalhadores Rurais do Estado da Bahia (AATR) na defesa de seus direitos.

Quadro 1 - Comunidades remanescentes de quilombos do Recôncavo em processo de regularização fundiária

\begin{tabular}{|c|c|c|c|c|}
\hline Nome & Cidade & $\begin{array}{c}\text { Ano de } \\
\text { certificação } \\
\text { pela FCP }\end{array}$ & $\begin{array}{c}\text { Ano de } \\
\text { abertura do } \\
\text { processo no } \\
\text { INCRA }\end{array}$ & $\begin{array}{c}\text { Fase da } \\
\text { regularização } \\
\text { fundiária }\end{array}$ \\
\hline Alto do Cruzeiro e Acupe & Santo Amaro & 2010 & 2010 & $\begin{array}{c}\text { Apenas processo } \\
\text { aberto }\end{array}$ \\
\hline Baixa da Linha & Cruz das Almas & 2010 & 2011 & $\begin{array}{c}\text { Apenas processo } \\
\text { aberto }\end{array}$ \\
\hline $\begin{array}{c}\text { Brejo do Engenho da } \\
\text { Guaíba }\end{array}$ & Cachoeira & 2006 & 2012 & $\begin{array}{c}\text { Apenas processo } \\
\text { aberto }\end{array}$ \\
\hline Buri & Maragojipe & 2009 & 2010 & RTID $^{78}$ publicado \\
\hline
\end{tabular}


O Negro no Recôncavo da Bahia: reflexões sobre construções identitárias, retóricas...

\begin{tabular}{|c|c|c|c|c|}
\hline $\begin{array}{l}\text { Calolé, Tombo, Imbiara, } \\
\text { Engenho da Vitória e } \\
\text { Caimbongo Velho }\end{array}$ & Cachoeira & 2004 & 2009 & RTID publicado \\
\hline Cambuta & Santo Amaro & 2010 & 2010 & $\begin{array}{c}\text { Apenas processo } \\
\text { aberto } \\
\end{array}$ \\
\hline $\begin{array}{c}\text { Caonge, Calemba, Dende, } \\
\text { Engenho da Ponte e } \\
\text { Engenho da Praia }\end{array}$ & Cachoeira & 2004 & 2011 & RTID publicado \\
\hline Dende & Maragojipe & 2006 & 2011 & $\begin{array}{c}\text { Apenas processo } \\
\text { aberto }\end{array}$ \\
\hline Engenho da Cruz & Cachoeira & 2007 & 2011 & $\begin{array}{c}\text { Apenas processo } \\
\text { aberto }\end{array}$ \\
\hline $\begin{array}{l}\text { Engenho Novo Vale do } \\
\text { Iguape }\end{array}$ & Cachoeira & 2005 & 2012 & $\begin{array}{c}\text { Relatório } \\
\text { Antropológico }\end{array}$ \\
\hline Enseada do Paraguaçu & Maragojipe & 2006 & 2008 & $\begin{array}{c}\text { Apenas processo } \\
\text { aberto }\end{array}$ \\
\hline Porto de Dom João & $\begin{array}{l}\text { São Francisco do } \\
\text { Conde }\end{array}$ & 2013 & 2013 & $\begin{array}{c}\text { Apenas processo } \\
\text { aberto }\end{array}$ \\
\hline $\begin{array}{c}\text { Quizanga, Guerem, Baixa } \\
\text { do Guaí, Tabatinga }\end{array}$ & Maragojipe & 2006 & 2007 & RTID publicado \\
\hline Salamina Putumuju & Maragojipe & 2004 & 2005 & $\begin{array}{c}\text { Decreto } \\
\text { Presidencial, } \\
\text { INCRA emitido } \\
\text { na posse } \\
\text { de parte do } \\
\text { território. }\end{array}$ \\
\hline São Braz & Santo Amaro & 2009 & 2009 & $\begin{array}{c}\text { Relatório } \\
\text { Antropológico }\end{array}$ \\
\hline $\begin{array}{l}\text { São Francisco do } \\
\text { Paraguaçu }\end{array}$ & Cachoeira & 2005 & 2006 & $\begin{array}{c}\text { Portaria de } \\
\text { Reconhecimento } \\
\text { Publicada }\end{array}$ \\
\hline São Tiago do Iguape & Cachoeira & 2006 & 2008 & $\begin{array}{c}\text { Relatório } \\
\text { Antropológico }\end{array}$ \\
\hline Tabuleiro da Vitória & Cachoeira & 2013 & 2013 & $\begin{array}{c}\text { Apenas processo } \\
\text { aberto }\end{array}$ \\
\hline Vila Guaxinim & Cruz das Almas & 2012 & 2014 & $\begin{array}{c}\text { Apenas processo } \\
\text { aberto }\end{array}$ \\
\hline
\end{tabular}

Fonte: sites do INCRA e da FCP

Como em outros contextos de emergência de identidades quilombolas ${ }^{9}$, a mobilização das comunidades em termos étnicos foi precedida por outras formas de luta que não lograram reconhecimento 
pleno dos seus direitos. Nesse caso específico, foi a articulação dessas coletividades em: a) 1997 pela criação de uma Reserva Extrativista na Baia do Iguape (como estratégia política de enfrentamento dos danos causados pela Barragem Pedra do Cavalo instalada nessa baia em 1985); b) a partir dos anos 2000 pela inclusão de seus territórios (mais especificamente da Baixa do Guaí) na unidade de conservação para evitar a sua expropriação; e c) entre 2004 e 2005 para pressionar o IBAMA a criar o conselho gestor da unidade de conservação para fazer frente aos problemas enfrentados (tais como os danos gerados pelo início das operações da Usina Pedra do Cavalo na barragem de mesmo nome) . Diante da negativa do órgão ambiental em incluir essas áreas na reserva e em decorrência do contato com a legislação quilombola no processo de formação do conselho gestor da RESEX, os grupos começaram a demandar reconhecimento estatal nesses termos (CARVALHO; HEIMER, 2015).

A situação mais próxima da titulação é a da comunidade de Salamina Pitumuju, no município de Maragojipe, mas tanto o seu processo quanto o da comunidade de São Francisco do Paraguaçu foram prejudicados diretamente pela implantação do Estaleiro Enseada do Paraguaçu, como veremos mais adiante.

A maior parte das comunidades que compõem o Projeto Rota da Liberdade, embora tenham sido as primeiras a se autoidentificarem como quilombolas, ainda se encontram nos estágios iniciais do processo de regularização, com a conclusão do Relatório Técnico de Identificação e Delimitação (RTID). Esse é o caso de Caonge, Dendê, Engenho da Ponte e Engenho da Praia. Parte dessa morosidade se deve a contestação judicial da sua certificação conjunta pela Fundação Cultural Palmares por parte dos fazendeiros da região, temerosos que a demanda territorial desses grupos também fosse unificada. A exceção é São Francisco do Paraguaçu, que já teve a Portaria de Reconhecimento do seu território publicada, mas enfrenta uma série de problemas como será exposto posteriormente.

No contexto de elaboração dos relatórios antropológicos sobre as comunidades de Caonge, Calemba, Dende, Engenho da Ponte e Engenho da Praia, verificou-se que a produção artesanal do azeite de 
dendê - denominação de uma das comunidades - também representa para elas uma das atividades identificadas como símbolos da sua trajetória histórica e social, juntamente com a pesca e a mariscagem. Ao dendê estão associados o passado escravo e o candomblé, este último elemento central na lógica de parentesco e organização social das comunidades pertencentes a este território étnico. O fruto indica locais, saberes e fazeres que, no contexto dos conflitos territoriais, permitem o diálogo entre essas comunidades quilombolas e os demais grupos sociais com os quais interage. Evidencia-se, desse modo, que a fabricação do azeite de dendê e o candomblé, elementos acionados no Projeto Rota da Liberdade, integram as retóricas nativas sobre raça, etnia e cultura.

O êxito de fixação e permanência dessas populações em seus territórios está diretamente relacionado com o declínio econômico que atingiu o Recôncavo a partir de fins do século XIX e se intensificou ao longo do século $\mathrm{XX}^{10}$. Isso porque ele restringiu, durante muito tempo, os conflitos pelas terras com os fazendeiros da região.

Contudo, nos últimos anos essa realidade sofreu intensas transformações, principalmente devido ao processo de instalação de empreendimentos de grande porte, tais como: o Eco-Resort Ilha de Cajaíba, no arquipélago de mesmo nome, localizado entre os municípios de Santo Amaro e São Francisco do Conde, e o Estaleiro Enseada do Paraguaçu, na cidade de Maragojipe. Esses dois projetos afetaram e/ ou afetarão direta ou indiretamente as comunidades remanescentes de quilombos do Recôncavo.

A aquisição da Ilha de Cajaíba em 2006 por um grupo empresarial de desenvolvimento imobiliário, a Property Logic, para a construção de um Eco-Resort de luxo ${ }^{11}$, deflagrou a mobilização de várias comunidades remanescentes de quilombo pelo reconhecimento estatal de sua existência e de seus direitos territoriais e simbólicos sobre o arquipélago. A Comunidade Remanescente de Quilombo de São Braz, situada na cidade de Santo Amaro, pleiteia essa área como parte do seu território, ainda que reconheça que ela é utilizada por outras coletividades e esteja disposta a compartilhar o seu uso com elas ${ }^{12}$. 
A ocupação dela remonta aos tempos coloniais. Seu primeiro proprietário foi Mem de Sá, o terceiro governador-geral do Brasil. Contudo, foi José Joaquim de Argolo e Queirós, membro ilustre de uma família de abastados senhores de engenho da Bahia, o construtor das edificações presentes até hoje na ilha, como o sobrado e o engenho que datam do séc. XVIII ${ }^{13}$. Seu filho, Alexandre Gomes de Argolo Ferrão (1800-1870), militar que participou do combate aos portugueses pela Independência da Bahia e aos revoltosos durante a Sabinada, foi presidente e vice-presidente da Província da Bahia em várias ocasiões e tornou-se Barão de Cajaíba em 1841. O Barão ficou famoso por sua crueldade com escravos e inimigos a partir da prática de jogá-los, ainda vivos, em um fosso da ilha. Desse modo, o local de martírio dos cativos representa uma parte importante da história de sofrimento e de resistência dessas comunidades negras oriundas dos antigos engenhos da região. Diante da possibilidade concreta de impedimento de utilização da Ilha de Cajaíba (como tradicionalmente tem sido feito ao longo dos anos), os quilombolas têm se mobilizado politicamente pela regularização de seus territórios e pela garantia de preservação e de acesso a eles (CARVALHO, 2016a).

A ilha ocupa um lugar singular na memória coletiva dessas comunidades como podemos constatar pela narrativa de um dos integrantes mais velhos de São Braz, em Santo Amaro, Sr. Manoel Messias Pereira, no contexto de elaboração do relatório antropológico do grupo:

A gente ficava na Ilha de Cajaíba. Já cansei de pegar camarão lá. Ali tinha alçapão e tudo ali, pra matar o povo. O mais velho me contava assim... que o pessoal ia trabalhar quando era a hora do pagamento o Barão chamava: "Vem cá, vem receber seu dinheiro". Aí o cara ia procurar...quando chegava lá...não é por aí. Você tem que vir por aqui". Aí sumia. Pegava o dinheiro do povo, chegava lá e caía no alçapão ${ }^{14}$.

As histórias sobre o Barão de Cajaíba, sua crueldade com seus subordinados e os locais de martírio e morte no arquipélago foram transmitidas oralmente através das gerações e são articuladas as experiências conflituosas vivenciadas pelos quilombolas na 
contemporaneidade. O alçapão situa-se na ordem das dificuldades encontradas pelos negros da região no período pós-abolição e a necessidade dos antigos senhores de terem mão de obra suficiente para o trabalho nas usinas de cana-de-açúcar em decadência. É nesse momento que o uso da maré e da ilha por parte dessas populações se tornou mais intenso (FERNANDES, 2015).

O arquipélago também tem grande importância econômica para esses grupos. Homens, mulheres e até mesmo crianças costumam se deslocar até a ilha para coletar frutos, como o cajá, a goiaba e o jenipapo, especialmente no mês de maio. Eles são vendidos in natura ou na forma de polpa pelos acostamentos das estradas próximas ou para atravessadores, orientando-se especialmente para a produção de licores caseiros largamente consumidos nos festejos juninos. Essa atividade também se configura como uma importante forma de complementação da renda familiar. Por isso, mesmo diante das proibições de ingresso na Ilha de Cajaíba, os moradores de São Braz e de outras comunidades quilombolas da região continuam visitando o local ao longo de todo o ano e ali coletam jaca, sapoti, coco, tamarindo, manga, banana, cacau, araçá, dendê, cipó e tala de licuri. Além disso, nas suas imediações peixes, camarões e mariscos se reproduzem (CARVALHO, 2016a).

O Conselho Pastoral dos Pescadores (CPP $)^{15}$ começou a atuar em 2007 em defesa das condições de trabalho para os pescadores na comunidade de São Braz, demandando canoas e serviços públicos, como o posto de saúde local. O agente da CPP, Gilmar Santos, introduziu a discussão sobre as comunidades remanescentes de quilombos junto ao grupo. Trata-se de uma coletividade majoritariamente negra, com várias expressões culturais (Festa e Lavagem de São Braz ${ }^{16}$, Samba Chula ${ }^{17}$, Bumba meu boi, Maculelê $\hat{e}^{18}$ e capoeira) que remetem à ancestralidade africana e à escravidão, entre elas as atividades produtivas artesanais tradicionais (pesca e mariscagem). As ruínas do solar e do engenho de São Braz foram elementos considerados relevantes pelos integrantes da comunidade ao momento do debate com o agente da pastoral, levandoos a considerar que o entendimento de sua identidade étnica poderia ser balizado segundo esses termos. Supõe-se aqui uma correspondência entre o termo quilombola e alguns atributos relativos à raça, cultura, modo de vida, além de evidências arqueológicas (CARVALHO, 2016a). 
A emergência social e política desses agrupamentos étnicos deve ser compreendida como um processo de etnogênese, isto é, de reconstrução identitária. Tal dinâmica não está alheia às legislações que garantem direitos especiais a grupos particulares sendo, muitas vezes, resultado indireto e não planejado de políticas públicas específicas. A atualização identitária se dá através da experiência de participação política, que algumas organizações etnopolíticas - como o movimento negro - proporcionam. Estas experiências contribuem para dignificar o elemento étnico e dar um sentido positivo às condições quilombola e negra (BARTOLOMÉ, 2006).

Entendemos - do mesmo modo como o faz Arruti (2006) para a situação da comunidade negra do Mocambo - que embora o "objeto político-administrativo" comunidade remanescente de quilombo só possa ser criado pela intervenção do Estado, não é possível desconsiderar que os grupos organizados antecedem tal objetivação e em alguns casos podem ser os propositores de uma auto-objetivação. Isso quer dizer que aquele conjunto de transformações próprias ao processo de territorialização ${ }^{19}$ pode anteceder a territorialização propriamente dita, e que o Estado não é o único agente relevante nesse contexto, ainda que seja uma figura central. Em relação a esse último aspecto, é preciso considerar a atuação de uma gama de mediadores ${ }^{20}$, tais como militantes de movimentos sociais negros, políticos, advogados, pesquisadores, entre outros personagens, que contribuem de forma relevante nestes processos.Dentre as comunidades negras que utilizam a ilha e que têm procedimento aberto junto ao INCRA, São Braz foi a primeira a ser objeto de estudo antropológico. A questão da garantia de acessibilidade aos recursos disponíveis em Cajaíba para esta e outras coletividades tornou-se tema recorrente da investigação etnográfica realizada por este órgão estatal. É relevante observar que a preocupação central diz respeito à manutenção do usufruto comum do arquipélago pelos diversos grupos e não sobre com qual associação ficará o título da área.

A resposta do Estado aponta para a regularização fundiária dessa área, em benefício de uma associação quilombola. Esta solução pode 
em vez de equacionar um problema, criar um conflito futuro, pois introduz uma hierarquia jurídica entre os grupos na relação com o espaço das terras do arquipélago até então inexistente.

É possível que nos defrontemos com algo similar ao ocorrido diante a emergência da categoria jurídica dos remanescentes de quilombos, alvo de reflexão de Almeida (2011). Segundo o autor, certas situações que se impõem pela via do conflito social, muitas vezes, não correspondem aos critérios norteadores das categorias classificatórias de organização da estrutura agrária brasileira, por apresentarem formas de apropriação dos recursos da natureza que não são individualizadas. Para abarcar tais manifestações marginais, cunhou-se a expressão "ocupações especiais". A designação tenta dar conta das chamadas "terras de uso comum", que compreendem uma constelação de situações de apropriação de recursos naturais empregados em uma multiplicidade de formas e de combinações que oscilam entre o uso privado e o comum. Essa apropriação de recursos é constantemente atravessada por fatores étnicos, de parentesco, de sucessão, históricos, político-organizativos e econômicos, consonantes às práticas e sistemas de representações particulares.

As "terras de preto", como são popularmente chamadas, teriam sido estabelecidas após a emergência do Artigo 68 do Ato das Disposições Constitucionais Transitórias, que contempla, ao menos em tese, os remanescentes de quilombos. Contudo, é provável que estejamos enfrentando uma nova defasagem entre as categorias estatais vigentes e a realidade extremamente diversa e complexa que figura no cotidiano das comunidades negras brasileiras, em particular, das baianas. Embora o Estado se proponha a considerar as especificidades territoriais destes grupos, ainda persiste a tentativa de conexão unívoca entre um grupo e um espaço geográfico claramente delimitado.

Como mencionado anteriormente, o empreendimento turístico na Ilha de Cajaíba não foi o único a ameaçar as comunidades remanescentes de quilombo do Recôncavo. O Estaleiro Enseada do Paraguaçu, localizado na cidade de Matagojipe e estimado em 2 bilhões de reais, é uma unidade industrial de construção de embarcações, como plataformas e navios. O consórcio responsável pelo projeto foi 
composto de empresas Odebrecht, OAS, UTC Engenharia e Kawasaki. Considerado um dos maiores empreendimentos da iniciativa privada na Bahia e na indústria naval brasileira, ele faz divisa com a Comunidade Remanescente de Quilombo da Enseada e com a Reserva Extrativista Marinha Baia do Iguape.

A poligonal original da RESEX abrangia a área onde foi construído o estaleiro. Após modificação para viabilizar o projeto ela se sobrepôs ao território da Comunidade Remanescente de Quilombo de São Francisco do Paraguaçu, trazendo novas implicações ao seu processo de regularização territorial. Processo esse que marcado por denúncias de fraude na certificação ${ }^{21}$, assim como contestações administrativas e judiciais por parte dos fazendeiros da região. Nesse momento, é a própria comunidade que questiona as consequências da inclusão de parte do seu território na RESEX.

A área incorporada consiste num núcleo urbano habitado por 450 famílias e conta com praça, escola e posto de saúde, engloba as propriedades dos fazendeiros que tem demonstrado maior contrariedade ao processo de regularização quilombola seja através de recursos administrativos, seja através de ações judiciais. Com a sobreposição, as desapropriações não serão mais atribuição do INCRA, mas sim do Instituto Chico Mendes de Conservação da Biodiversidade (ICMBio), órgão ligado ao Ministério do Meio Ambiente (MMA) (CARVALHO; HEIMER, 2015; CARVALH0, 2016b).

De acordo com o órgão ambiental, ele tem um passivo de 10 milhões de hectares de terras a regularizar em unidades de conservação no país, orçamento diminuto e número de funcionários insuficientes para a tarefa. O que nos leva a crer que a regularização fundiária por esta instituição seria tão ou mais morosa do que pelo INCRA. Outrossim, essa porção do território não poderá mais ser titulada em nome da associação quilombola como anteriormente previsto, tornando-se propriedade da União sob concessão de uso as comunidades tradicionais existentes no interior da RESEX. Desse modo, é possível que mesmo após desapropriados, alguns fazendeiros pleiteiem a permanência no local, e que moradores quilombolas que não desenvolvem atividades extrativistas tenham dificuldade em obter esse privilégio (CARVALHO; HEIMER, 2015; CARVALHO, 2016b). 
A discussão do plano de manejo em São Francisco do Paraguaçu já tem delineado novos conflitos, agora entre quilombolas e o ICMBio. No interior da unidade de conservação não é possível criar animais de grande porte (como bois, vacas e cavalos) e a expansão ou construção de edificações precisa da permissão do órgão ambiental. Muitas pessoas criam animais desse tipo no local e dependem dessa atividade para o seu sustento. Assim como as reformas ou construção de casas são extremamente frequentes no povoado para acompanhar o crescimento das famílias. Desse modo, a inclusão na RESEX não proporcionou proteção as moradias quilombolas e ao seu modo de vida como alegado pelo ministro do MMA para modificar a área da unidade de conservação, mas impõe restrições que são incompatíveis com as necessidades do grupo para reproduzir-se social e culturalmente (CARVALHO; HEIMER, 2015; CARVALHO, 2016b).

A alteração da poligonal foi considerada uma medida necessária para o empreendimento, mas os efeitos dela não foram contabilizados como impacto danos no Estudo de Impacto Ambiental/Relatório de Impacto ao Meio Ambiente (EIA/RIMA) do estaleiro ainda que já fosse de conhecimento público a demanda territorial do grupo e a sobreposição pudesse ser precocemente identificada. Além disso, a mudança foi executada sem consulta prévia a coletividade, conforme preconiza a Convenção 169 da Organização Internacional do Trabalho, sobre Povos Indígenas e Tribais, da qual o Brasil é signatário através do decreto presidencial 5.051, de 19 de abril de 2004. Mesmo assim, seus representantes se posicionaram contrários a modificação do perímetro da reserva em inúmeras oportunidades (CARVALHO; HEIMER, 2015; CARVALHO, 2016b).

Tal contexto evidencia que, mesmo nos casos em que existe legislação protegendo os interesses das comunidades tradicionais, e das comunidades remanescentes de quilombos em particular, prevalece o ideal de desenvolvimento e a inexorabilidade dos projetos de intervenção territorial, que resulta na limitação dos estudos de proposição de medidas paliativas para a mitigação e compensação dos danos derivados do projeto, configurando um paradigma de adequação ambiental (ZHOURI; GESTA, 2013). 
Como apontamos anteriormente, no início dos anos 2000 as coletividades quilombolas tinham demandado alteração da poligonal da RESEX para proteção de seus territórios, sem lograr sucesso. A época o órgão ambiental responsável alegou que a reserva era majoritariamente aquática e que, portanto, não deveria incorporar novas áreas terrestres. Uma década depois, diante da premissa de que um estaleiro naval teria que ser instalado no local, a mudança da poligonal é feita e recai sobre um perímetro terrestre densamente habitado, sob a pretensa alegação de que, desse modo, se estaria protegendo um patrimônio histórico e cultural quilombola. Quando a proteção estatal é requerida pelos próprios grupos, ela é negada tendo por base "critérios técnicos" que não são levados em consideração no segundo momento. Quando ela é concedida, ocorre a revelia dos sujeitos e se materializa em toda a sorte de restrições e obstáculos a efetivação de seus direitos.

A empresa Paraguaçu Engenharia, que adquiriu terras na região em função da expectativa de valorização dos imóveis com a construção do estaleiro, obteve uma suspensão parcial dos efeitos do Decreto Presidencial de Interesse Social do território de Salamina Putumuju, no município de Maragojipe. Trata-se de uma situação inédita que pode se tornar um precedente legal negativo para a regularização fundiária dos territórios quilombolas em âmbito nacional.

As ações para aumentar a profundidade da Baia do Iguape com o intuito de viabilizar a construção e deslocamento das plataformas e outras embarcações resultou na impossibilidade de pesca e mariscagem por seis meses naquela localidade, atingindo diversos grupos quilombolas da região. O consórcio responsável pela construção do estaleiro realizou um cadastro dos pescadores atingidos para o recebimento de uma indenização temporária, mas contestou o número de pessoas que declaravam realizar essa atividade, bem como ignorou a existência e o prejuízo material das marisqueiras, cuja profissão não é legalmente reconhecida.

Além disso, a Comunidade quilombola de Enseada, que se localiza há menos de 500 metros do empreendimento, não teve sequer seu relatório antropológico elaborado mesmo tendo sido considerada prejudicada diretamente por ele. Com a construção do estaleiro, seus integrantes passaram a enfrentar grande dificuldade de acesso aos locais 
tradicionais de pesca e mariscagem que se dava por trilhas na mata que foi suprimida no processo. Agora eles dependem da disponibilidade de barcos e recursos financeiros para adquirir combustível para sua locomoção a esses espaços. Em 2014, com a vinda de mais de sete mil trabalhadores para os canteiros da obra, aumentou a criminalidade, violência, tráfico de drogas, prostituição e assédio contra as mulheres na localidade. Atualmente, menos de 200 pessoas trabalham no estaleiro para manutenção. Isso se deve aos desdobramentos da Operação Investigativa da Polícia Federal denominada Lava Jato, que implicou, inclusive, na prisão dos dirigentes das empresas responsáveis pelo empreendimento. A suspensão do seu funcionamento gerou uma crise econômica sem precedentes na região, atingindo todos aqueles que de uma maneira ou outra prestavam ou vendiam serviços e mercadorias para seus empregados.

\section{Considerações Finais}

Ainda que tenhamos identificado conflitos no processo de exploração turística da Festa da Boa Morte, constatamos que o seu reconhecimento cultural como patrimônio nunca fomentou controvérsias, mas por que não? Tal processo não valoriza apenas a população negra, mas a religiosidade popular sincrética e mestiça, e de certo modo a identidade regional. Embora a irmandade adquira importância para vários segmentos negros nacionais e estrangeiros, não implica na configuração de um espaço de referência exclusivo, tal como a ideia dos territórios quilombolas sugere. Enquanto a regularização fundiária das comunidades remanescentes de quilombos geralmente se dá através da desconstituição de formas de apropriação territorial consideradas legitimas, a turistização e patrimonialização da Irmandade da Boa Morte e das comunidades quilombolas por meio do Projeto Rota da Liberdade não coloca em risco a existência de outros bens culturais já reconhecidos e não implica em desapropriações para a efetivação desse tipo de reconhecimento.

As políticas públicas de turismo e salvaguarda de patrimônio, embora tenham avançado com a inclusão de outros grupos formadores da sociedade brasileira, como as populações indígenas e negras, não 
deixam de ser uma maneira de integrar tais singularidades numa totalidade maior que é a nação. É uma forma de reconhecimento que em um primeiro momento opera com a admissão da diferença (característica que justifica a sua inclusão) para depois acomodála na narrativa da identidade nacional e regional, como expressão representativa da sua variação interna.

Ainda que tanto a Festa da Boa Morte quanto o turismo étnico de base comunitária das comunidades quilombolas de Cachoeira sejam formas de exploração econômica de elementos culturais tradicionalmente associados a identidade afro-brasileira, eles são protagonizados pelos próprios grupos, nos seus termos, de acordo com seus valores. Além disso, representam movimentos de resistência as tentativas históricas de submissão e encapsulamento perpetradas pela igreja católica e de depreciação e demonização contemporâneas ocasionadas pela inserção massiva das religiões neopentecostais na região.

A regularização fundiária dos territórios quilombolas também apresenta os seus impasses. Como aqueles advindos do embate entre o caráter genérico da intervenção estatal e as especificidades vividas pelas comunidades que acabam por gerar ou complexificar tensões e conflitos intra e extragrupais, como procuramos ilustrar com a descrição das situações vivenciadas pelas coletividades de São Braz e São Francisco do Paraguaçu. Contudo, apesar da morosidade, essa forma de reconhecimento estatal se configura na principal modalidade acionada por essas coletividades para fazer frente a projetos turísticos e de desenvolvimento que ignoram e ameaçam seus modos de ser e de viver.

As dificuldades enfrentadas pelas Comunidades Remanescentes de Quilombos do Recôncavo em terem seus direitos territoriais reconhecidos por parte do Estado nos permitem tecer algumas considerações sobre aquilo que chamamos de espaço da diferença negra no Brasil. O país, como nação, estabeleceu formas específicas de construção e relação com a sua alteridade interior, configurando-se assim numa formação da diversidade (SEGATO, 1998). Mas qual lugar a população negra tem nessa formação? No ordenamento simbólico brasileiro, não se reconhece o negro como sujeito político ou de direito, mas apenas 
como objeto cultural, como marco da nacionalidade e da civilização brasileira. O ordenamento jurídico, embora aponte para direções menos simbólicas, tende a ficar encapsulado pela lógica cultural (GUIMARÃES, 2001). O campo da cultura continua sendo o lugar por excelência reservado ao tema da população negra em nosso país; isto é o espaço da diferença. Os negros não são vistos como tendo ou pretendendo ter uma identidade cultural distinta da população brasileira em geral, tal como os grupos indígenas, que justifique direitos coletivos (ARRUTI, 2006; CARVALHO, 2008).

\section{Notas}

1 Devido à escassez de documentos antigos relativos a essa organização, pesquisadores divergem quanto ao período de sua fundação e a sua ligação com a confraria homônima que existiu em Salvador nessa mesma época nas imediações da Barroquinha.

2 A conformação da irmandade propiciou a feitura de várias mães de santo e o surgimento dos terreiros mais antigos e tradicionais da cidade e região.

3 A Secretaria de Turismo foi criada em 2007. Anteriormente, a pasta era vinculada à Secretaria de Cultura. Em 2015, a Setur incorporou a sua estrutura a antiga Empresa de Turismo da Bahia S.A. (Bahiatursa). Antes empresa de economia mista, o órgão foi transformado em uma Superintendência de Fomento ao Turismo do Estado da Bahia, com a finalidade de gerenciar e executar a Política de Fomento e Desenvolvimento do Turismo, bem como a promoção de eventos turísticos, no âmbito estadual.

4 Em 2005, o Samba de Roda do Recôncavo Baiano foi reconhecido como obra-prima do Patrimônio Oral e Imaterial da Humanidade pela UNESCO. Entre 2004 e 2007 foram registrados como patrimônio cultural brasileiro: o Samba de Roda do Recôncavo Baiano; o Ofício das Baianas de Acarajé; o Jongo do Sudeste e o Samba de Terreiro, Partido-alto e Samba-enredo. Em 2006, o IPAC registrou como patrimônio imaterial a Capoeira. Em 2010, foi a vez do Desfile dos Afoxés, juntamente com a Festa da Boa Morte.

5 Há 414 anos se iniciou em Cachoeira, BA, a construção do primeiro templo religioso na então Vila de Nossa Senhora do Rosário do Porto da Cachoeira. A Capela de Nossa Senhora D'Ajuda, padroeira dos senhores de engenho foi dedicada inicialmente à devoção de Nossa Senhora do Rosário, Padroeira da Vila. Com o passar dos anos e o desenvolvimento da Vila, os devotos de Nossa Senhora D'Ajuda, agregados na Irmandade dedicada a Santa deram início às comemorações de louvor, sempre, na primeira quinzena de novembro. Os festejos, com extrema participação dos devotos, especialmente constituídos por senhores de engenho, se transformou numa festa de enormes proporções, quando à Vila se dirigiam de todas as regiões habitadas da Província Baiana devotos da milagrosa Santa D'Ajuda. Os senhores de engenho durante o ensejo louvavam ao sucesso da colheita da cana-de-açúcar, base de toda economia da época. A participação dos senhores de engenho nos festejos influenciou na participação dos seus escravos, que consequentemente, com o passar dos tempos, 
integraram o rol dos devotos e com adaptações, principalmente na parte profana da festa, deram a tonalidade dos festejos em Louvor a Nossa Senhora D'Ajuda. A festa hoje se destaca no Recôncavo Baiano como um importante folguedo popular, reunindo manifestações originalíssimas, personalidades do imaginário, criados na fusão cultural detonado com a miscigenação racial que se instalou na Bahia, principalmente no Recôncavo, especialmente em Cachoeira. São cabeçorras, mandus, mascarados, velhos, meninos, meninas, diabos, santos e o povo, pelas ruas calçadas com paralelepípedos, à sombra dos seculares sobrados, cantando músicas e letras singulares, das históricas filarmônicas, que com instrumentos de sopro (trompetes, trombones, baixos e clarinetes) e percussão (caixas, tambores, bumbos e pratos) fazem uma belíssima festa, totalmente singular e popular.

6 O processo de regularização fundiária de territórios quilombolas se desdobra em várias fases ou etapas, desde a abertura do processo, certificação da Fundação Cultural Palmares, produção do Relatório Técnico de Identificação e Delimitação (que envolve a produção de um relatório antropológico, levantamento fundiário e consulta a órgãos públicos), publicização, prazo de apresentação e análise de contestações, emissão de portaria de reconhecimento do território e desapropriação. Trata-se de um procedimento bastante complexo e moroso, que na maioria dos casos demora anos. Para saber mais consultar: http://cpisp.org.br/direitosquilombolas/ caminho-da-titulacao-2/.

7 Relatório Técnico de Identificação e Delimitação, que abrange um conjunto diversificado de informações de ordem antropológica, histórica, econômica, social, geográfica e documental.

8 Relatório Técnico de Identificação e Delimitação, que abrange um conjunto diversificado de informações de ordem antropológica, histórica, econômica, social, geográfica e documental.

9 Estamos falando aqui em processos de etnogênese (BANTON, 1977), onde as identidades se constituem num movimento dinâmico de apropriação da condição étnica e de interpretação dos eventos políticos sob um contexto de disputa territorial. Os papeis do movimento negro e de outros mediadores, como advogados e antropólogos, por exemplo, são relevantes na medida em que contribuem para a organização política desses grupos em termos étnicos com vistas a garantir direitos territoriais sobre as áreas que ocupam.

${ }^{10}$ Os fatores que contribuíram para o declínio econômico da região foram: o agravamento da crise nas lavouras de cana-de-açúcar e fumo resultante da concorrência de outros estados do Brasil e países; o crescimento populacional da cidade de Salvador e a elevação dos seus padrões de vida que exigiu um abastecimento mais numeroso incentivando o desenvolvimento de novas localidades de produção alimentar; e a superposição de uma rede de estradas de rodagem que privilegiou outros municípios próximos da capital em detrimento dos antigos caminhos e ferrovias do Recôncavo.

11 A ilha foi adquirida em 2006, pela empresa de desenvolvimento Imobiliário Property Logic, com sede em Málaga, na Espanha, e que possui projetos de resorts de luxo no Marrocos e no Brasil. O projeto de aquisição da ilha consistia na implantação de um complexo turístico intitulado Ilha de Cajaíba Beach e Golf Resort e previa a construção de SPA hotéis, residências particulares de luxo, campo de golfe com 18 buracos, centro eqüestre, clube de pólo, piscina olímpica, academia de tênis, estádio de futebol, marina, clube náutico, lojas e vilas de entretenimento. Seu desenvolvimento ocorreria em quatro etapas e tinha a expectativa de gerar 6 mil empregos diretos. Em 2009, o Rezidor Hotel Group, associado à grife italiana Missoni, anunciou a construção de um hotel de luxo para este complexo com inauguração 
prevista para 2015. O hotel contaria com 118 habitações e 32 vilas. Em setembro de 2012, o grupo Property Logic anunciou o cancelamento do projeto Cajaíba Beach e Golf Resort em virtude da crise financeira internacional. Um dos proprietários do empreendimento revelou que mantinha a intenção de construir um resort com 50 apartamentos e 50 bangalôs em sociedade com empresários russos.

12 A pesquisa de doutorado realizada por uma das autoras desse artigo acerca dos usos e significados atribuídos à Ilha de Cajaíba, identificou outras comunidades quilombolas que se valem desse lugar de forma mais direta em função das atividades desenvolvidas para sustento, conforme acima mencionado. São elas: Acupe e Cambuta, município de Santo Amaro; Caboto, município de Candeias; Monte Recôncavo e Porto Dom João, município de São Francisco do Conde; Comunidade da Ilha de Maré, situada no município de Salvador. Nota-se que, independentemente da distância geográfica, é possível afirmar que a Ilha é entendida pelas comunidades como importante referência histórica e cultural ligada à sua etnicidade a partir de situações comuns a todas elas. Trata-se de um destino compartilhado pelos quilombolas do Recôncavo de modo não isolado dos demais contextos envolvendo conflito territorial e políticas de turismo étnico. Ou seja, os discursos construídos pelas comunidades quilombolas sobre a Ilha configuram uma das formas de se legitimarem como grupos politicamente organizados mas que encontram-se em condições desfavoráveis de reconhecimento étnico e territorial por parte das políticas de Estado, mais especificamente, aquelas ligadas ao turismo étnico em função das manipulações feitas acerca do que é dito (ou o que poder ser dito) sobre suas trajetórias (FERNANDES, 2016).

13 Trata-se de um patrimônio arquitetônico reconhecido pelo Instituto do Patrimônio Artístico e Cultural da Bahia (IPAC).

14 Sr. Manoel Messias Pereira, 89 anos. Entrevista realizada em 09/07/2013 por Mariana Balen Fernandes.

15 O Conselho Pastoral dos Pescadores (CPP) é uma pastoral social ligada à Comissão Episcopal para o Serviço da Caridade Solidária, Justiça e Paz da Conferência Nacional dos Bispos do Brasil (CNBB). O CPP é composto por agentes pastorais, leigos, religiosos e padres comprometidos com o Serviço junto aos pescadores e às pescadoras artesanais para a construção de uma sociedade mais justa e solidária. O trabalho pastoral com os pescadores foi iniciado em 1968, nas praias de Olinda (PE), pelo Frei Alfredo Schnuettgen. Mais tarde, o trabalho se espalhou para os estados de Alagoas, da Paraíba e do Rio Grande do Norte. Em 1976, com apoio de Dom Helder Câmara, o CPP foi reconhecido em nível nacional pela CNBB, tendo como coordenador e animador o próprio Frei Alfredo. Assim, o CPP se expandiu para outros estados do Nordeste e para outras regiões do país, tornando-se, em 1988, uma instituição jurídica.

${ }^{16}$ A Festa da Lavagem é parte das atividades que integram o calendário religioso católico da Festa de São Braz, realizada no mês de janeiro pela Comunidade Quilombola São Braz. A Lavagem ocorre um dia antes da procissão do santo e consiste na presença de membros das religiões afrobrasileira (candomblé e umbanda) que ao longo do percurso feito pelas ruas e residências da Comunidade, realizam a bênção com o banho de alfazema. A lavagem representa também uma das formas de uso do espaço pelas famílias quilombolas que atribuem significados aos locais onde a procissão das baianas de axé passa, limpa e abençoa.

17 Samba de roda típico de Santo Amaro, onde uma dupla de cantadores canta a chula e a outra dupla, reforçada pelo coro de mulheres, responde o relativo, um 
verso menor que arremata a chula. Na parte instrumental do samba chula, uma das sambadeiras samba com passos miudinhos e percorre toda a roda até dar uma umbigada em outra sambadeira que aguarda a próxima chula ser cantada para sambar. As chulas tratam de temas do cotidiano, como amores, trabalho, religiosidade e de sofrimentos que remontam ao tempo da escravidão.

18 Forma de dança folclórica de origem afrobrasileira e indígena, vinculada à capoeira, que simula uma luta tribal usando dois bastões como arma, com os quais os participantes devem desferir e aparar golpes no ritmo da música.

19 Trata-se do movimento pelo qual um objeto político administrativo - remanescentes das comunidades dos quilombos - se transforma numa coletividade organizada, formulando uma identidade própria, instituindo mecanismos de tomada de decisão e representação e reestruturando as suas formas culturais (OLIVEIRA, 1998).

20 Referem-se aos agentes que se relacionam com diferentes espaços sociais, interligando-os, transcodificando suas informações e influenciando as várias dimensões pertinentes aos grupos sociais a que estão vinculados. Ver: WOLF, Eric. "Aspectos das relações de grupos em uma sociedade complexa". In: WOLF, Eric; FELDMAN-BIANCO, Bela; RIBEIRO, Gustavo Lins. Antropologia e Poder. Brasília: Ed. da Universidade de Brasília (UNB); São Paulo: Imprensa Oficial do Estado de São Paulo, Editora Unicamp, 2003.

${ }^{21}$ No ano de 2007, denúncias sobre fraude no procedimento de certificação envolvendo a Comunidade Remanescente de Quilombo de São Francisco do Paraguaçu, ganharam espaço na mídia nacional. Mesmo depois de uma sindicância da Fundação Cultural Palmares (FCP) apurar que não houve irregularidades nesse caso, novas regras foram estabelecidas para a obtenção da certidão de autoidentificação, tornando mais burocratizada a etapa inicial do reconhecimento estatal desses grupos.

\section{Referências}

ALMEIDA, Alfredo Wagner Berno de. Quilombolas e novas etnias. Manaus: Edições da Universidade do Estado do Amazonas (UEA), 2011. 196p.

ARRUTI, José Maurício P. Andion. Mocambo: Antropologia e História do processo de formação quilombola. Bauru: Edusc, 2006. 370p.

BANTON, Michael. A ideia de raça. São Paulo: Edições 70; Martins Fontes, 1977. 199p.

\section{BARTH, Fredrik. O guru, o iniciador e outras variações} antropológicas. Rio de Janeiro: Contra Capa, 2000. 243p.

BARTOLOMÉ, Miguel Alberto. As etnogêneses: velhos atores e novos papéis no cenário cultural e político. Revista Mana, Museu Nacional $(\mathrm{MN})$ da Universidade Federal do Rio de Janeiro (UFRJ), Rio de Janeiro, n. 1, v. 12, p. 39-68, 2006. 
CARVALHO, Ana Paula Comin de. O Planeta dos negros no mundo dos brancos: estudo sobre a manutenção e atualização das fronteiras étnicas de uma comunidade negra na cidade de Canoas/RS. 2003. 162p. Dissertação (Mestrado) - Universidade Federal do Rio Grande do Sul, Porto Alegre, 2003.

CARVAlHO, Ana Paula Comin de. O espaço da diferença no Brasil: Etnografia de políticas públicas de reconhecimento territorial e cultural negro no sul do país. 2008. 235p. Tese (Doutorado) - Universidade Federal do Rio Grande do Sul, Porto Alegre, 2008.

CARVAlHO, Ana Paula Comin de. Comunidades Remanescentes de Quilombos do Recôncavo da Bahia: conflitos territoriais e articulações identitárias. In: CARVALHO, A. P. C.; MULLER, C. B.; OLIVEIRA, R. (org.). Territorialidades Negras em Questão. Rio de Janeiro/Cachoeira: Editora Fino Traço/NEAB/UFRB, 2016a. p. 13-28.

CARVALHO, Ana Paula Comin de. Tecnologias de governo, regularização de territórios quilombolas, conflitos e respostas estatais. Horizontes Antropológicos, Porto Alegre, ano 22, n. 46, jul.-dez, p. 131-157, 2016 b.

CARVALHO, Ana Paula Comin de; HEIMER. MIchael. Análise dos impactos do Estaleiro Enseada do Paraguaçu, Maragojipe/BA, com o auxílio da Geotecnologia. In: IV CONGRESSO LATINO AMERICANO DE ANTROPOLOGIA, Cidade do México/UNAM, out. 2015. Anais [...], Cidade do México, 2015.

CASTRO, Armando Alexandre Costa de. A Irmandade da Boa Morte: memória, intervenção e turistização da festa em Cachoeira, Bahia. 20015 182p. Dissertação (Mestrado) - Universidade Federal da Bahia, 2005. 182 p.

CRUZ, Ana Paula Batista da Silva.Costurando os retalhos: um estudo sobre a comunidade Santiago do Iguape. In: III EBECULT. UFRB, Cachoeira, 2012. Paper, Cachoeira, 2012.

FERNANDES, Mariana Balen. Direitos coletivos, patrimônio e conflito: a relação entre políticas de estado e a Comunidade Quilombola São Braz (BA). In: CARVALHO, A. P. C.; MULLER, C. B.; OLIVEIRA, R. (org.).

Territorialidades Negras em Questão. Rio de Janeiro; Cachoeira: Editora Fino Traço; NEAB/UFRB, 2015. p. 123-146.

FERNANDES, Mariana Balen. Ilha de Cajaíba: lugar de pertencimento e territorialidades nas Comunidades Quilombolas Acupe, São Braz e Porto Dom João, Recôncavo Baiano. 2016. 251p. Tese (Doutorado) Universidade Federal da Bahia, Salvador, 2016.

FRANCISCO, Dalmir. Comunicação, identidade cultural e racismo. In: FONSECA, Maria Nazareth Soares (org.). Brasil Afro-brasileiro. Belo Horizonte: Ed. Autêntica, 2000. p. 117-152. 
GUIMARÃES, Antonio Sérgio Alfredo. Nacionalidade e novas identidades raciais no brasil: uma hipótese de trabalho. In: SOUZA, Jessé de (org.). Democracia hoje: novos desafios para a teoria democrática contemporânea. Brasília: Ed. Universidade de Brasília, 2001. p. 387-414.

OLIVEIRA, João Pacheco de. Uma etnologia dos índios misturados? Situação colonial, territorialização e fluxos culturais. Revista Mana, Rio de Janeiro, n. 1, v. 4, p. 47-77, 1998.

QUEIROZ, Mércia Maria Aquino de. Turismo de raízes na Bahia: um estudo sobre a dinâmica do Turismo Étnico (Afro) na Bahia - os casos do Pelourinho e da Festa da Boa Morte/Cachoeira. 2008. 230p. Dissertação (Mestrado) - Universidade Federal da Bahia, Salvador, 2008.

\section{SEGATO, Rita Laura. Alteridades históricas/identidades políticas:} uma crítica a las certezas del pluralismo global. Brasília: Departamento de Antropologia da UNB, 1998. Série Antropologia n. 234. 28p.

SOUZA, Wiltercia Silva de. A guerra santa entre a Irmandade da Boa Morte e a Igreja Católica, Bahia, 1989/1990. In: III ENCONTRO ESTADUAL DE HISTÓRIA, Salvador, 2006. Anais [...], Salvador, BA, 2006.

WOLF, Eric. Aspectos das relações de grupos em uma sociedade complexa. In: WOLF, Eric. Antropologia e Poder: Contribuições de Eric Wolf. Bela Feldman-Bianco e Gustavo Lins Ribeiro. Brasília; São Paulo: Ed. da UNB; Imprensa Oficial do Estado de São Paulo; Editora Unicamp, 2003. p. 73-91.

ZAGATTO, Bruna Pastro. Eu sou marisqueira, lavradora e quilombola: uma análise do processo de construção de identidade nas comunidades rurais do Guai, Maragojipe, Bahia. 2011. 176p. Dissertação (Mestrado) Universidade Federal da Bahia, Salvador, 2011.

ZHOURI, Andréa; GESTA, Raquel Oliveira. Conflitos entre desenvolvimento e meio ambiente no Brasil: desafios para a antropologia e os antropólogos. In: FELDMAN-BIANCO, Bela (org.). Desafios da Antropologia Brasileira. Brasília, DF: ABA, 2013. p. 75 - 108.

Recebido em: 24/08/2017

Aceito em: 1\%07/2019

\section{Mariana Balen Fernandes}

Doutorado em Antropologia. Professora do Centro de Cultura, Linguagens e Tecnologias Aplicadas (CECULT) da Universidade Federal do Recôncavo da Bahia (UFRB).

Endereço para correspondência: Rua do Imperador, 09, Cais de Araújo Pinho Santo Amaro da Purificação, Bahia. CEP 44.200-000.

E-mail: balen.mariana@gmail.com marianabalen@ufrb.edu.br 